\title{
CD14/-159 and TNF $\alpha /-308$ Promoter Polymorphisms are not associated with Development of Idiopathic Neonatal Hepatitis among Filipinos
}

\author{
Florence Giannina F. San Juan, ${ }^{1}$ Annavi Marie G. Villanueva, ${ }^{1}$ \\ Germana Emerita V. Gregorio ${ }^{2}$ and Catherine Lynn T. Silao 2,3 \\ ${ }^{1}$ College of Medicine, University of the Philippines Manila \\ ${ }^{2}$ Department of Pediatrics, College of Medicine and Philippine General Hospital, University of the Philippines Manila \\ ${ }^{3}$ Institute of Human Genetics, National Institutes of Health, University of the Philippines Manila
}

\begin{abstract}
Objective. To determine if the CD14/-159 and the TNFa/-308 single nucleotide polymorphisms (SNPs) are associated with the development of Idiopathic Neonatal Hepatitis (INH) in Filipino children.

Methods. Genomic DNA from 33 patients diagnosed with INH and 33 age- and sex-matched controls, children without any liver disease, were recruited. Baseline serum total bilirubin (TB), direct bilirubin (DB), and alkaline phosphatase (ALP) of the patients were obtained from their medical records. Genotypes for CD14/159 and TNFa/-308 were determined via PCR and direct sequencing.

Results. No significant difference was seen between the frequency of the CD14/-159 T allele $(p=0.86)$ nor the TNFa/-308 A allele $(p=0.62)$ between INH patients and controls. There was also no significant difference between the genotypic distribution of the INH and control populations for both CD14/-159 $(p=0.54)$ and TNFa/-308 $(p=0.62)$. There were also no significant differences noted between the different genotypes of CD14/159 and TNFa/-308 and levels of alkaline phosphatase $(p=0.65$, $p=0.91)$, total bilirubin $(p=0.89, p=0.75)$, and direct bilirubin $(p=0.93, p=0.68)$.
\end{abstract}

Conclusion. In this preliminary study, CD14/-159 and TNFa/-308 showed no association with the development of INH among Filipinos.

Key Words: Idiopathic neonatal hepatitis, CD14, TNFa, promoter polymorphism, Filipino

Florence Giannina F. San Juan and Annavi Marie G. Villanueva contributed equally to this paper (Joint first authorship).

Paper and poster presented at the Association of Philippine Medical Colleges Student Research Competition (Basic Sciences Category), February 6, 2015, Davao Medical School Foundation.

Corresponding author: Annavi Marie G. Villanueva, MD College of Medicine

University of the Philippines Manila

547 Pedro Gil St., Ermita, Manila 1000 Philippines

Telephone: +632 2454242

Email: annavi_v@yahoo.com

\section{Introduction}

Cholestasis, a condition in which bile flow from the liver is impaired, may be caused by two events - a problem in bile formation of hepatocytes, and the obstruction of bile flow through the biliary trees ${ }^{1}$ both of which lead to a buildup of bile substances in the blood. Bile is produced through bile salt uptake of hepatocytes from the blood, followed by excretion of bile salts into the biliary canaliculus. These processes involve various membrane transporters found on both the basolateral and the canalicular aspects of hepatocytes. ${ }^{2}$ Cholestatic jaundice affects approximately 1 in every 2,500 infants worldwide with biliary atresia and idiopathic neonatal hepatitis (INH) as the most common causes. ${ }^{3}$

Idiopathic neonatal hepatitis (INH) has an incidence of 1 in 4,800 to 9,000 live births in North America. ${ }^{4}$ A systematic review done by Gottesman, et al. estimates INH to comprise $26.0 \%$ of cases of conjugated hyperbilirubinemia in infancy. However, because of recent developments in determining possible causes of INH, the disorder now only partakes $15 \%$ of neonatal cholestasis cases. ${ }^{5}$ In parts of Asia, majority of neonatal cholestasis cases are still idiopathic. In Malaysia, INH comprises $38 \%$ of their neonatal cholestasis cases ${ }^{6}$ while in Thailand $23 \%$ of these cases were idiopathic. ${ }^{7}$ In a fiveyear period (2006-2010), the Philippine General Hospital had 231 cases of INH, where giant cell hepatitis was proven through percutaneous liver biopsy. ${ }^{8}$

Being a diagnosis of exclusion, a patient is said to have INH after obtaining negative results in workups for other etiologies - ultrasound of the hepatobiliary tree, metabolic newborn screening and determination of any evidence of infection such as toxoplasmosis, rubella, cytomegalovirus, herpes and hepatitis $B$ virus. Measurement of liver function tests is done including direct bilirubin (DB), indirect bilirubin (IB), and alkaline phosphatase (ALP) as a measure of cholestasis and transaminases to determine degree of hepatocellular damage. A patient with INH clinically presents with jaundice, hepatosplenomegaly, elevated serum bilirubin and transaminases. Histopathologic features of INH include lobular disarray due to swelling of hepatocytes, focal hepatic necrosis, giant cell transformation, and extramedullary hematopoiesis. ${ }^{2}$ 
The etiology of INH is still unknown. Since 1970, possible causes of INH which include genetic and different metabolic disorders have been determined. This led to an approximately $50 \%$ decrease in the percentage of infants with neonatal cholestasis diagnosed with the disease. Despite the developments on the topic, a small number of patients were found not to have genetic defects, thereby, necessitating further research in order to determine the etiology of this disease. ${ }^{9}$

Recently, a study was published regarding the association of the CD14/-159 and $\mathrm{TNF} \alpha /-308$ promoter polymorphism to the development of $\mathrm{INH}^{10}$ and showed that there is a possible association between CD14/- 159 polymorphism and the development of INH.

The CD14 gene encodes a surface antigen that is mainly expressed on monocytes. The protein plays a role in the mediation of the innate immune response to lipopolysaccharide, an antigen produced by gram-negative bacteria. ${ }^{11}$ This suggests a possible etiology in which processes downstream of CD14 expression may be implicated in the development of INH.

The TNF $\alpha$ gene, on the other hand, is located in the Major Histocompatibility Complex Class 3 region on chromosome $6 .^{12,13} \mathrm{TNF} \alpha$ is a pro-inflammatory cytokine produced by Kupffer cells upon activation by various stimuli. A common stimulus is lipopolysaccharide, during hepatic clearance of infection. TNF $\alpha$ release leads to a downregulation of certain membrane transporters; thereby, causing a decrease in bile flow, ultimately leading to bile flow cholestasis. ${ }^{14}$ The TNF $\alpha$ promoter polymorphism G(308)A has been found to be associated with higher TNF $\alpha$ production, ${ }^{15}$ as well as various hepatobiliary conditions including faster clearance of HBV infection, allograft rejection in the liver, primary sclerosing cholangitis, ${ }^{10}$ chronic $\mathrm{HCV}$ infection ${ }^{15}$ with severe inflammation, and fibrosis in non-alcoholic fatty liver disease. ${ }^{16}$

This study, the first to be done on INH among Filipino patients, determined the association of $\mathrm{TNF} \alpha /-308$ and CD14/-159 in the development of idiopathic neonatal hepatitis among Filipino children.

\section{Methods}

\section{Study Population}

As a preliminary study only, thirty-three Filipino children (16 males and 17 females) histologically diagnosed with INH at the Section of Gastroenterology, Hepatology and Nutrition of the Department of Pediatrics, University of the Philippines Manila - Philippine General Hospital were included in this study. Exclusion criteria were children diagnosed with neonatal cholestasis with an identified etiology, no informed consent, and those who had no liver biopsy. Thirty-three age- and sex-matched children (16 males and 17 females) without any history of jaundice or other liver conditions, having their laboratories taken at the Department of Laboratories, UP-PGH were recruited as controls.

\section{Polymorphism Analysis}

Genomic DNA was extracted from peripheral blood of both patients and controls using the QIAmp DNA Mini/Midi Kit (Valencia, CA, USA). A 347bp fragment with the single nucleotide promoter polymorphism TNF- $\alpha-308$ was amplified using the primers $5^{\prime}$ - CTCAGGACTCAACACAGC - 3' and 5' - TCGGTTTCTTCTCCATCG - 3'. The primers used to amplify the $295 \mathrm{~kb}$ fragment containing the CD14 C(159)T polymorphism were $5^{\prime}$ - ATCATCCTTTTCCCACACC $-3^{\prime}$ and 5' - AACTCTTCGGCTGCCTCT - 3'.

Each PCR reaction mixture for both CD14/-159 and TNF $\alpha /$-308 contained $1 \mathrm{uL}$ of $10 \mathrm{x}$ PCR buffer, $0.3 \mathrm{uL}$ of 50 $\mathrm{mM} \mathrm{MgCl2}, 0.2 \mathrm{uL}$ of $10 \mathrm{mM}$ dNTP, $0.2 \mathrm{uL}$ of $10 \mathrm{uM} \mathrm{CD14}$ or $\mathrm{TNF} \alpha$ forward primer, $0.2 \mathrm{uL}$ of $10 \mathrm{uM} \mathrm{CD14}$ or TNF $\alpha$ reverse primer and $0.2 \mathrm{uL}$ of 50x TiTaq (1U TiTaq), $100 \mathrm{ng}$ of genomic DNA diluted to $10 \mathrm{uL}$ with distilled, deionized water.

The amplification profile for CD14/-159 is as follows: initial denaturation $\left(7 \mathrm{mins}, 95^{\circ} \mathrm{C}\right), 35$ cycles of denaturation $\left(30 \mathrm{~s}, 95^{\circ} \mathrm{C}\right)$, annealing $\left(30 \mathrm{~s}, 62.5^{\circ} \mathrm{C}\right)$, and extension $(30 \mathrm{~s}$, $\left.72^{\circ} \mathrm{C}\right)$, followed by final extension $\left(10 \mathrm{mins}, 72^{\circ} \mathrm{C}\right)$ and for $\mathrm{TNF} \alpha /$-308: initial denaturation $\left(7 \mathrm{mins}, 94^{\circ} \mathrm{C}\right), 35$ cycles of denaturation $\left(30 \mathrm{~s}, 94^{\circ} \mathrm{C}\right)$, annealing $\left(30 \mathrm{~s}, 59.7^{\circ} \mathrm{C}\right)$, and extension $\left(30 \mathrm{~s}, 72^{\circ} \mathrm{C}\right)$, followed by final extension (10 mins, $\left.72^{\circ} \mathrm{C}\right)$.

All PCR products, stained with GelRed ${ }^{\mathrm{TM}}$ were run on $2 \%$ agarose gels and visualized using UV transillumination. The amplicons were subsequently directly sequenced using the ABI 3730XL DNA ANALYZER (Applied Biosystems, USA).

\section{Biochemical Characteristics}

Baseline serum levels of alkaline phosphatase, total bilirubin, direct and indirect bilirubin were obtained from the patient's medical records. These blood tests were done at the Department of Laboratories of the Philippine General Hospital using standard techniques.

\section{Statistical Analysis}

Allele and genotype frequencies were estimated by the gene counting method. Odds ratios together with 95\% confidence intervals were calculated using the $\chi^{2}$ test of association and the Hardy-Weinberg equilibrium was tested for each SNP using the $\chi^{2}$ test.

Mean and standard deviations of alkaline phosphatase and conjugated bilirubin levels were computed from the information collected from the patients. ANOVA was used to determine if there was a significant difference between the biochemical characteristics of patients with different genotypes. 
A p-value of less than 0.05 was considered statistically significant for all statistical tests performed. All statistical tests were performed using OpenEpi v3.0.

\section{Ethical Considerations}

The protocol underwent review and approval by the Research Implementation and Development Office and the University of the Philippines Manila - Research Ethics Board (UPM-REB). Written informed consents were obtained from the parents or the legal guardians prior to inclusion of the participants in the study.

\section{Results}

\section{Study Participants}

A total of 33 cases and 33 controls were recruited for the study (Table 1). The age of the participants recruited ranged from 1 month to 13 months of age. There was no significant difference $(p=0.86)$ between the ages of the case $(3.18 \pm 1.96$ months) and control (3.27 \pm 2.31 months) groups. The study population was composed of 16 pairs of male and 17 pairs of female participants.

Table 1. Demographic Characteristics of the Study Population

\begin{tabular}{lccc}
\hline & INH $(\mathbf{n}=\mathbf{3 3})$ & Control $(\mathbf{n}=\mathbf{3 3})$ & p-value (t-test) \\
\hline Age (months) & $3.18 \pm 1.96$ & $3.27 \pm 2.31$ & 0.86 \\
Sex (M/F) & $16 / 17$ & $16 / 17$ & \\
\hline
\end{tabular}

\section{Allele and Genotype Frequency among INH Patients and Controls}

PCR amplicons (347bp TNF $\alpha$ fragment and $295 \mathrm{bp}$ CD14 fragment) were sequenced to determine the presence of the TNF $\alpha$ and CD14 promoter polymorphisms in all study participants. Thirty-three (33) age- and sex-matched INH cases and controls were analyzed for TNF $\alpha$ and CD14, respectively.

There was no significant difference between the allelic distribution of the A and G allele for TNF $\alpha /-308(p=0.62)$ and the $\mathrm{C}$ and $\mathrm{T}$ allele for CD14/-159 ( $\mathrm{p}=0.86$ ) for INH cases and controls (Table 2).

TNF $\alpha /-308$ A/A genotype was absent among INH patients and controls. Using the dominant model (A/A + G/A vs $G / G)$, there was no significant difference between the $G / G$ genotype of INH patients and controls $(p=0.62)$. Using a recessive model $(\mathrm{T} / \mathrm{T}$ vs $\mathrm{C} / \mathrm{T}+\mathrm{C} / \mathrm{C})$, there was no significant difference between the $\mathrm{T} / \mathrm{T}$ genotype of INH patients and controls $(p=0.54)$. The results show that neither the TNF $\alpha /$ 308 nor the CD14/-159 promoter polymorphisms confer an increased risk for developing INH in the Filipino population.

Biochemical Characteristics of INH Patients and their Relationship to CD14/-159 and TNFa/-308 Genotype

There was no significant difference between the levels of alkaline phosphatase, total bilirubin and direct bilirubin among the different genotypes (Table 3).

\section{Discussion}

No study has so far been conducted regarding the possible role of genes in idiopathic neonatal hepatitis (INH) here in the Philippines.

A study conducted by Shih and colleagues has shown the association of CD14/-159 promoter polymorphism with biliary atresia and INH in Taiwanese children. ${ }^{1}$ In the same study, it was found that TNF $\alpha /-308$ promoter polymorphism was not associated with the said diseases. However, as shown in Table 2, this does not hold true for the Philippine population; both the CD14/-159 (C>T) and TNF $\alpha /-308(\mathrm{G}>\mathrm{A})$ polymorphisms were not associated with the development of INH in neonates in Filipinos.

\section{TNF alpha and Liver Diseases}

TNF $\alpha$ is a cytokine secreted by macrophages and cytotoxic T lymphocytes in the liver. It has pro-inflammatory and antiviral properties that give it a major role in hepatic injury and fibrosis. ${ }^{17}$

Other TNF $\alpha$ gene SNPs associated to liver diseases, such as hepatitis $B$ virus infection, are $-1031 \mathrm{~T}>\mathrm{C},-863 \mathrm{C}>\mathrm{A}$,

Table 2. TNF $\alpha$-308 and CD14-159 Polymorphism Among Patients with INH and Controls

\begin{tabular}{|c|c|c|c|c|}
\hline & INH (\%) $(n=33)$ & Control $(\%)(n=33)$ & Odds Ratio $(95 \%$ CI) & p-value (2-tail) \\
\hline \multicolumn{5}{|c|}{ CD14 C(-159)T Polymorphism } \\
\hline \multicolumn{5}{|l|}{ Allele } \\
\hline $\mathrm{C}$ & $38(57.58 \%)$ & 37 (56.06\%) & $0.94(0.47,1.87)$ & 0.86 \\
\hline $\mathrm{T}$ & $28(42.42 \%)$ & 29 (43.94\%) & & \\
\hline \multicolumn{5}{|l|}{ Genotype } \\
\hline $\mathrm{C} / \mathrm{C}$ & $12(36.36 \%)$ & $9(27.0 \%)$ & & \\
\hline $\mathrm{C} / \mathrm{T}$ & $14(42.42 \%)$ & $19(57.58 \%)$ & & \\
\hline $\mathrm{T} / \mathrm{T}$ & $7(21.21 \%)$ & $5(15.0 \%)$ & $1.51(0.43,5.35)$ & 0.54 \\
\hline \multicolumn{5}{|c|}{ TNF $\alpha$ G(-308)A Polymorphism } \\
\hline \multicolumn{5}{|l|}{ Allele } \\
\hline A & $2(3.03 \%)$ & $1(1.51 \%)$ & $2.03(0.18,22.96)$ & 0.62 \\
\hline G & $64(96.97 \%)$ & $65(98.48 \%)$ & & \\
\hline \multicolumn{5}{|l|}{ Genotype } \\
\hline $\mathbf{A} / \mathbf{A}$ & 0 & 0 & & \\
\hline A/G & $2(6 \%)$ & $1(3.03 \%)$ & & \\
\hline G/G & 31 (93.94\%) & 32 (96.97\%) & $2.07(0.18,23.94)$ & 0.62 \\
\hline
\end{tabular}


Table 3. Biochemical Characteristics of INH Patients According to TNF $\alpha-308$ and CD 14 -159 Genotypes

\begin{tabular}{|c|c|c|c|c|c|c|c|}
\hline & \multicolumn{3}{|c|}{ TNF $\alpha$-308 Polymorphism } & \multicolumn{4}{|c|}{ CD14 C(-159)T Polymorphism } \\
\hline & $\mathrm{G} / \mathrm{A}(\mathrm{n}=2)$ & $\mathrm{G} / \mathrm{G}(\mathrm{n}=31)$ & p-value & $T / T(n=7)$ & $\mathrm{C} / \mathrm{T}(\mathrm{n}=14)$ & $\mathrm{C} / \mathrm{C}(\mathrm{n}=12)$ & p-value \\
\hline Alkaline Phosphatase (IU/L) & $509 \pm 140$ & $536.38 \pm 320.96$ & 0.91 & $629.64 \pm 448.49$ & $535.05 \pm 183.88$ & $480.56 \pm 400.12$ & 0.65 \\
\hline Total Bilirubin (mg/dL) & $10.44 \pm 2.18$ & $11.03 \pm 4.39$ & 0.75 & $11.70 \pm 3.75$ & $10.77 \pm 3.94$ & $10.86 \pm 5.17$ & 0.89 \\
\hline Direct Bilirubin $(\mathrm{mg} / \mathrm{dL})$ & $7.67 \pm 0.89$ & $6.71 \pm 3.21$ & 0.68 & $7.16 \pm 2.57$ & $6.69 \pm 3.08$ & $6.62 \pm 3.67$ & 0.93 \\
\hline
\end{tabular}

$-857 \mathrm{C}>\mathrm{T}$ and $-238 \mathrm{G}>\mathrm{A} .{ }^{12,18}$ It is possible that other TNF $\alpha$ SNPs besides the studied $-308 \mathrm{G}>\mathrm{A}$ are implicated in INH. These SNPs can be studied in the future to determine possible associations with INH in the Filipino population.

A meta-analysis by Chen et al. revealed that the TNF $\alpha /$ 308 polymorphism is not associated with the development among Asian populations. Their results showed that among Asians, the homozygous A/A and the heterozygous G/A alleles were the most common. ${ }^{19}$ This data supports the results of this study, wherein participants are all Filipinos and are from the Asian population.

Other contributory factors, including the role of other cytokines should also be taken into consideration. Bader El Din, et al. showed that TGFB1/-159 polymorphism had a synergistic effect to $\mathrm{TNF} \alpha /-308$ in hepatic fibrosis progression..$^{20}$ Hence, there is a need to analyze multiple polymorphisms and the role of other inflammatory factors in the development of INH.

\section{CD14 and Liver Diseases}

The CD14/ -159 polymorphism has been associated with many diseases such as myocardial infarction, ${ }^{21}$ alcoholic liver disease ${ }^{22}$ and other atopic diseases. ${ }^{23}$ The CD14 gene expresses a protein which is significant for lipopolysaccharide-dependent signal transduction ${ }^{24}$ and thus, the general hypothesis is that the subsequent immune responses generated through the endotoxin receptor CD14 plays a role in the development of the different diseases.

The CD14/ -159 polymorphism affects expression of the endotoxin receptor, with the $\mathrm{T}$ allele generating a higher expression of the receptor because of decreased affinity of an inhibitory factor for transcription (Sp3) to the regulatory region. ${ }^{25}$ It is expected then, that an individual with a T allele would generate a more potent immune response through the CD14 receptor pathway as compared to an individual with a $\mathrm{C}$ allele because of the higher expression of the said protein. Thus, the more potent inflammatory response contributes to the pathology of different diseases.

Different studies have also shown conflicting results with regard to this hypothesis. While some studies have shown the association of the TT genotype with elevated sCD14 levels and cirrhosis, ${ }^{26}$ the study conducted by Shih et al. showed that those carrying the $\mathrm{T}$ allele developed cirrhosis but had lower sCD14 levels.

Other studies regarding CD14/ -159 polymorphism and IgE circulation have also been conducted. However, studies associating the CD14/ -159 polymorphism with $\operatorname{IgE}$ circulation have also produced conflicting results; some have shown the association of the CC genotype with elevated IgE levels $^{27}$ while others have shown otherwise. ${ }^{28-29}$ The discrepancies thus lead us to question the exact role of the CD14/ -159 polymorphism in the development of different diseases especially in inflammation. It may be that CD14 is only one of the many different factors that affect the outcome of these diseases.

To explain the differences, Vercelli suggests that there exists an "endotoxin switch" wherein differences in the environmental exposure to endotoxin may have an effect on the modulation of the polymorphism; that exposure to different antigen concentrations would result in opposite profiles of Th differentiation. ${ }^{30}$ In his model, when a population is exposed to very low and very high endotoxin loads, Th responses would be similar across the population and genetic differences would have little contribution to these responses. Polymorphisms only come into play within a narrow range of endotoxin load. These populations which are exposed to intermediate levels of endotoxin are more sensitive to small variations in CD14 expression..$^{30}$

This hypothesis was confirmed by a study of Eder et al. Their study showed that at different levels of exposure, CD14/ -159T polymorphism would have different effects. They found out that CD14/ -159T is neutral when tested for association with serum $\operatorname{IgE}$ levels in the totality of the population when exposure is not taken into account. At intermediate levels of exposure, the polymorphism is protective against increased IgE while at high exposure, it is associated with high IgE levels. ${ }^{31}$ This may then explain the differing results of this study to the study done by Shih et al. which was done in Taiwanese children consulting at Kaohsiung Chang Gung Memorial Hospital. The environmental exposures of the Filipino children studied may differ from the environmental factors of the Taiwanese children. Hence, it is also important to keep in mind that diseases are not merely the product of genetics but also a product of epigenetics and other factors, including environmental exposures that may alter genetic expression.

The discrepancies may also be accounted for by the different disease entities between the studies. The etiology of INH in the Philippines may differ from the etiology of INH in other countries since INH may actually be regarded as a hodgepodge of different diseases. ${ }^{9}$

\section{Biochemical Parameters and Genotypic Distribution in INH Cases}

Total bilirubin, direct bilirubin and alkaline phosphatase levels of INH patients with the different 
genotypes were compared. The data generated suggests that both the CD14/ -159 polymorphism and the TNF $\alpha /-308$ do not have any association with serum levels of these markers.

Mean levels of DB and ALP across different TNF $\alpha /-308$ genotypes among the group of INH cases did not vary significantly in this study. A research done by Xia et al. in 2011 on HBV infection showed that patients with TNF $\alpha /-308$ G/G genotype produced lower serum TNF-alpha than patients with the $\mathrm{A} / \mathrm{G}$ and the $\mathrm{A} / \mathrm{A}$ genotypes. ${ }^{13} \mathrm{~A}$ study on leptospiral hepatitis by Rizvi et al. in 2011 measured the mean ALT, AST and ALP levels together with TNF $\alpha$ levels in the serum. Though their patients had low TNF $\alpha$ levels (45.63pg/mL) in the blood, they observed elevated levels of ALT, AST and ALP. ${ }^{32}$

Compared to the findings of the aforementioned studies, the results of this research are contrasting. Majority of the INH cases had the G/G genotype, however, no significant difference was observed in the mean ALP levels of the groups with G/A genotype. However, a possible explanation for this is the low frequency of the G/A genotype in the sample of INH cases for this study. Conclusive comparisons between DB and ALP levels across different genotypes cannot be made.

A study by Poullis et al. showed that there was an association between CD14/-159 and liver enzyme levels in 310 British adults. In particular, CD14/-159 TT homozygotes had reduced levels of alanine aminotransferase, aspartate aminotransferase and gamma-glutamyl transpeptidase. ${ }^{33}$ However, a similar study conducted by Gonzalez-Quintela in the Spanish population showed that there was no such association and that CD14/-159 TT even had the highest serum gamma-glutamyl transpeptidase levels. ${ }^{34}$ Our results cannot conclude if there is a direct role of the CD14/-159 in the elevation of liver enzymes.

Since no association was found between the CD14 -159 promoter polymorphism and alkaline phosphatase and bilirubin levels, it may be suggested that CD14 expression does not play a direct role in the elevation of these markers.

\section{Conclusion}

Results of this preliminary study showed that the CD14/ -159 and the TNF $\alpha /-308$ polymorphisms do not have an association with the development of idiopathic neonatal hepatitis among Filipinos. There was no significant difference between the frequencies of $A$ and $G$ allele for TNF $\alpha /-308$ and $C$ and T allele for CD14/-159 for INH cases and controls. Lastly, there was no significant difference between the levels of alkaline phosphatase, total bilirubin, and direct bilirubin among the different genotypes for both polymorphisms.

The small population size of our study may have affected the outcome. Increasing the sample size would reflect data that is closer to the population mean and might uncover a significant difference in the biochemical markers between the three genotypes. For future studies, other factors that may affect gene expression may also be taken into consideration; this would include considering the synergistic effects of multiple polymorphisms thereby the need to analyze multiple polymorphisms. A more extensive study which include the maternal and prenatal history and other exposures of INH patients may also be done so as to take into account other external factors that may be associated with the development of INH, in concordance with their CD14 -159 SNP.

\section{Acknowledgment}

The researchers thank the University of the Philippines National Institutes of Health-Institute of Human Genetics for providing guidance and invaluable resources.

\section{Statement of Authorship}

Florence Giannina F. San Juan and Annavi Marie G. Villanueva contributed equally to this paper (Joint first authorship). All authors have approved the final version submitted.

\section{Author Disclosure}

All authors declared no conflict of interest.

\section{Funding Source}

This paper was funded by the Department of Science and Technology - Philippine Council for Health Research and Development, and by the UP Manila - National Institutes of Health, Institute of Human Genetics.

\section{References}

1. Feldman J, Friedman LS, Sleisenger MH. Gastrointestinal and Liver Disease: Pathophysiology, Diagnosis and Management. Philadelphia: Saunders; 2002.

2. Venigalla S, Gourley GR. Neonatal Cholestasis. Semin Perinatol. 2004; 28(5):348-55.

3. Treepongkaruna S, Jiltraruch S, Kodcharin P, et al. Neonatal intrahepatic cholestasis caused by citrin deficiency: prevalence and SLC25A13 mutations among Thai infants. BMC Gastroenterol. 2012; 12:141.

4. Suchy F. Neonatal cholestasis. Pediatr Rev. 2004; 25(11):388-96.

5. Gottesman LE, Del Vecchio MT, Aronoff SC. Etiologies of conjugated hyperbilirubinemia in infancy: a systematic review of 1692 subjects. BMC Pediatr. 2015; 15:192.

6. Lee WS, Chai PF, Boey CM, Looi LM. Aetiology and outcome of neonatal cholestasis in Malaysia. Singapore Med J. 2010; 51(5):434-9.

7. Aanpreung P, Laohapansang M, Ruangtrakool R, Kimhan J. Neonatal cholestasis in Thai infants. J Med Assoc Thai. 2005; 88 suppl 8:S9-15.

8. Vitug JD, Avila JM, Gregorio G. Histological pattern and outcome of Filipino children who underwent percutaneous liver biopsy: a five-year survey. Acta Med Philipp. 2015; 49(4):12-7.

9. Balistreri WF, Bezerra JA. Whatever happened to "Neonatal Hepatitis"? Clin Liver Dis. 2006; 10(1):27-53.

10. Shih HH, Lin TM, Chuang JH, et al. Promoter polymorphism of the CD14 endotoxin receptor gene is associated with biliary atresia and idiopathic neonatal cholestasis. Pediatrics. 2005; 116(2):437-41.

11. Wright SD, Ramos RA, Tobias PS, Ulevitch RJ, Mathison JC. CD14 a receptor for complexes of lipopolysaccharide (LPS) and LPS binding protein. Science. 1990; 249(4975):1431-3. 
12. Xia Q, Zhou L, Liu D, Chen Z, Chen F. Relationship between TNF-alpha gene promoter polymorphisms and outcomes of hepatitis B virus infections: a meta-analysis. PloS One. 2011; 6(5):1-8.

13. Nedwin GE, Naylor SL, Sakaguchi AY, et al. Human lymphotoxin and tumor necrosis factor genes: structure, homology and chromosomal localization. Nucleic Acids Res. 1985; 13(17):6361-73.

14. Farid S, Rashid L, Swelam S. Tumour Necrosis Factor-Alpha Gene Expression in Chronic Hepatitis C Virus Infection. EJHM. 2013; 51:395-404.

15. Mulder J, Karen SJ, Tietge UJ, Kuipers F. Nuclear receptors: mediators and modifiers of inflammation-induced cholestasis. Front Biosci. 2009; 14:2599-630.

16. Aller R, de Luis DA, Izola O, et al. G308A polymorphism of TNF-alpha gene is associated with insulin resistance and histological changes in nonalcoholic fatty liver disease patients. Ann Hepatol. 2010; 9(4):439-44.

17. Shmarina G, Pukhalsky A, Petrova N, et al. TNF gene polymorphisms in cystic fibrosis patients: contribution to the disease progression. J Transl Med. 2013; 11:19.

18. Kim YJ, Lee HS, Yoon JH, et al. Association of TNF-alpha promoter polymorphisms with the clearance of hepatitis B virus infection. Hum Mol Genet. 2003; 12(19):2541-6.

19. Chen D, Liu JL, Liu Y, Zhu J, Wang SW. Lack of an association between $308 \mathrm{G}>\mathrm{A}$ polymorphism of the TNF- $\alpha$ gene and liver cirrhosis risk based on a meta-analysis. Genet Mol Res. 2011; 10(4):2765-74.

20. Bader El Din NG, Farouk S, El-Shenawy R, et al. The synergistic effect of TNF $\alpha-308$ G/A and TGFB1-509 C/T polymorphisms on hepatic fibrosis progression in hepatitis $C$ virus genotype 4 patients. Viral Immunol. 2017; 30(2):127-35. doi:10.1089/vim.2016.0083

21. Zee RY, Lindpaintner K, Struk B, Hennekens CH, Ridker PM. A prospective evaluation of the CD14 C (-260)T gene polymorphism and the risk of myocardial infarction. Atherosclerosis. 2001; 154(3):699-702.

22. Jarvelainen HA, Orpana A, Perola M, Savolainen VT, Karhunen PJ, Lindros KO. Promoter polymorphism of the CD14 endotoxin receptor gene as a risk factor for alcoholic liver disease. Hepatology. 2001; 33(5):1148-53.

23. Woo JG, Assa'ad A, Heizer AB, Bernstein JA, Hershey GK. The -159 C-> $\mathrm{T}$ polymorphism of CD14 is associated with nonatopic asthma and food allergy. J Allergy Clin Immunol. 2003; 112(2):438-44.
24. Pugin J, Heumann ID, Tomasz A, et al. CD14 is a pattern recognition receptor. Immunity. 1994; 1(6):509-16.

25. LeVan TD, Bloom JW, Bailey TJ, et al. A common single nucleotide polymorphism in the CD14 promoter decreases the affinity of Sp protein binding and enhances transcriptional activity. J Immunol. 2001; 167(10):5838-44.

26. Melier C, Muhlbauer M, Johann M, et al. Different effects of a CD14 gene polymorphism on disease outcome in patients with alcoholic liver disease and chronic hepatitis C infection. World J Gastroenterol. 2005; 11(38):6031-7.

27. Han D, She W, Zhang L. Association of the CD14 gene polymorphism C-159T with allergic rhinitis. Am J Rhinol Allergy. 2010; 24(1):e1-3.

28. Ober C, Tsalenko A, Parry R, Cox N. A second-generation genomewide screen for asthma susceptibility alleles in a founder population. Am J Hum Genet. 2000; 67(5):1154-62.

29. Sahin F, Yildiz P, Kuzkucu A, Kuskucu MA, Karaca N, Midilli K. The effect of CD14 and TLR4 gene polymorphisms on asthma phenotypes in adult Turkish asthma patients: a genetic study. BMC Pulm Med. 2014:14:20.

30. Vercelli D. Learning from discrepancies: CD14 polymorphisms, atopy and the endotoxin switch. Clin Exp Allergy. 2003; 33(2):153-5.

31. Eder W, Klimecki W, Yu L. Opposite effects of CD14/-159 on total serum $\mathrm{IgE}$ in children raised in environment with different levels of microbial exposure [abstract]. Am J Respir Crit Care Med. 2003; 167(A943).

32. Rizvi M, Azam M, Ajmal MR, Shukla I, Malik A. Prevalence of leptospira in acute hepatitis syndrome and assessment of IL-8 and TNFalpha level in leptospiral hepatitis. Ann Trop Med Parasitol. 2011; 105(7):499-506.

33. Poullis AP, Shetty AK, Risley PD, Collinson PO, Mendall MA. Effect of the CD14 promoter polymorphism on liver function tests and its association with alcohol and obesity. Eur J Gastroenterol Hepatol. 2003; 15(12):1317-22.

34. Gonzalez-Quintela A, Campos J, Quinteiro C, Gude F. Liver enzyme levels in relation to a common polymorphism in the CD14 promoter gene. Eur J Gastroenterol Hepatol. 2007; 19(2):182-3. 